\title{
DỨBin
}

Technological University Dublin

ARROW@TU Dublin

Conference Papers

Antenna \& High Frequency Research Centre

2012-07-08

\section{Vivaldi Array for Generation of UWB Circular Polarization}

\author{
Adam Narbudowicz \\ Technological University Dublin \\ Matthias John \\ Technological University Dublin, matthias.john@tudublin.ie \\ Xiulong Bao \\ Technological University Dublin, xiulong.bao@tudublin.ie
}

See next page for additional authors

Follow this and additional works at: https://arrow.tudublin.ie/ahfrccon

Part of the Systems and Communications Commons

\section{Recommended Citation}

Narbudowicz, A. et al. (2012)Vivaldi Array for Generation of UWB Circular Polarization, IEEE International Symposium on Antennas and Propagation, Chicago, IL, USA, IEEE Antennas \& Propagation Society, Paper 360.2, 08/07/2012, doi:10.1109/APS.2012.6348767

This Conference Paper is brought to you for free and open access by the Antenna \& High Frequency Research Centre at ARROW@TU Dublin. It has been accepted for inclusion in Conference Papers by an authorized administrator of ARROW@TU Dublin. For more information, please contact arrow.admin@tudublin.ie, aisling.coyne@tudublin.ie,gerard.connolly@tudublin.ie. Funder: SFI 
Authors

Adam Narbudowicz, Matthias John, Xiulong Bao, and Max Ammann

This conference paper is available at ARROW@TU Dublin: https://arrow.tudublin.ie/ahfrccon/33 


\title{
Vivaldi Array for Generation of UWB Circular Polarization
}

\author{
Adam Narbudowicz, Matthias John, Xiulong Bao and Max J. Ammann \\ Antenna \& High Frequency Research Centre \\ Dublin Institute of Technology \\ Kevin St., Dublin, Ireland \\ adam.narbudowicz@mydit.ie
}

\begin{abstract}
A two antenna array is proposed for generating circular polarization for an ultra-wideband system. It consists of two orthogonal antipodal vivaldi antennas and a feed network which provides the appropriate phase and amplitude over the band of interest. The proposed structure is low cost and easy to manufacture, offering an axial-ratio bandwidth of $74 \%$.
\end{abstract}

\section{INTRODUCTION}

It is only recently that circularly-polarized (CP) antennas can provide good axial ratios (AR) across very wide bandwidths [1] (with the exception of spiral antenna). Furthermore, recent regulations by the FCC and European Commission triggered a proliferation of activity in ultrawideband (UWB) technology. Such systems enable low-power high-speed data transmission. It is therefore advantageous to combine the power efficiency/capacity of UWB with the advantages of circular polarization.

For classical narrowband systems CP can be achieved by employing two orthogonal linearly polarized antennas, fed with $90^{\circ}$ phase shift. In theory the same method can be applied to UWB, however practical constraints are more demanding. For narrowband systems the $90^{\circ}$ phase shift is usually generated by a delay line - a solution which is simple, but band limited. Recently UWB phase delay circuits have been developed, which employ aperture coupling mechanism [2]. These offer good phase stability across very wide bandwidths, but with disadvantages of substrate thickness being a design parameter and limited achievable phase shift.

The problem of dual orthogonal linearly polarized UWB antennas has been widely studied [3], [4]. Usually two orthogonal and intersecting antennas are introduced. Although suitable for many dual-polarized applications, this technique exhibits certain manufacturing disadvantages when a constant and stable phase shift is required across UWB. Although in [5] a four rigid horn antenna was successfully employed for UWB $\mathrm{CP}$, the structure is expensive to manufacture. Hence, in this paper a design involving two linearly polarized Vivaldi antennas is investigated. The structure consists of low-cost PCBs which are easy to fabricate.

\section{DESIGN}

The proposed structure comprises a feed network and two viavaldi antennas, positioned orthogonally to each other and spaced by distance $D$. The general scheme is shown in Fig. 1.

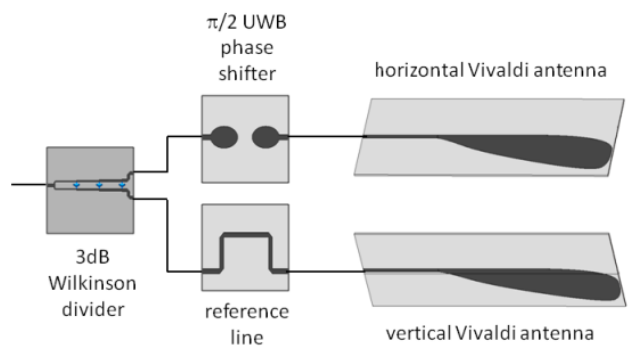

Figure 1. General scheme of the proposed antenna.

\section{A. Feed network}

The feed network consists of a $3 \mathrm{~dB}$ power divider, UWB $90^{\circ}$ phase shifter and a reference line, printed on Taconic RF$35,\left(\varepsilon_{\mathrm{r}}=3.5\right.$ and $\left.h=0.5 \mathrm{~mm}\right)$ and connected as seen in Fig. 1. Three different power dividers were tested for the configuration: a classical T-junction with tapered impedance transformers, a T-junction with slot-line transition [6] and a 3stage Wilkinson divider. Both T-junction dividers appeared to have poor isolation between the output ports. As the next stage is different for each output, this caused for some frequencies more than $3 \mathrm{~dB}$ variation between feeds of the two orthogonal antennas and degraded the AR at those frequencies (see Fig. 3). The use of a Wilkinson divider (with isolation below $20 \mathrm{~dB}$ across the band of interest) overcame this problem, providing smooth transmission coefficient with little variation between antenna feeds. UWB operation was achieved by employing three stages of the divider [7].

The UWB phase shifter is a 3 layered structure, which employs an aperture coupling technique [2]. A $45^{\circ}$ phase shift across UWB is achieved by coupling the signal through the elliptical hole in the ground plane to a microstrip line located on the other side of the substrate. Then another $45^{\circ}$ shift is applied in the same manner. The circuit with all relevant dimensions is shown on Fig. 2. Parameter values are: $W_{\text {slot }}=7.5 \mathrm{~mm}, L_{\text {slot }}=7.2 \mathrm{~mm}, W_{e l}=4.9 \mathrm{~mm}, L_{r e f}=7.2 \mathrm{~mm}$, $\Delta_{W}=2.4 \mathrm{~mm}, L_{W 1}=8.4 \mathrm{~mm}, L_{W 2}=9 \mathrm{~mm}$ and $D=21 \mathrm{~mm}$. 
Three stages of the divider have characteristic impedances of $89 \Omega$ (terminated by $\mathrm{R}_{1}=107 \Omega$ ), $71 \Omega$ (terminated by $\mathrm{R}_{2}=211 \Omega$ ) and $58 \Omega$ (terminated by $\mathrm{R}_{3}=400 \Omega$ ).

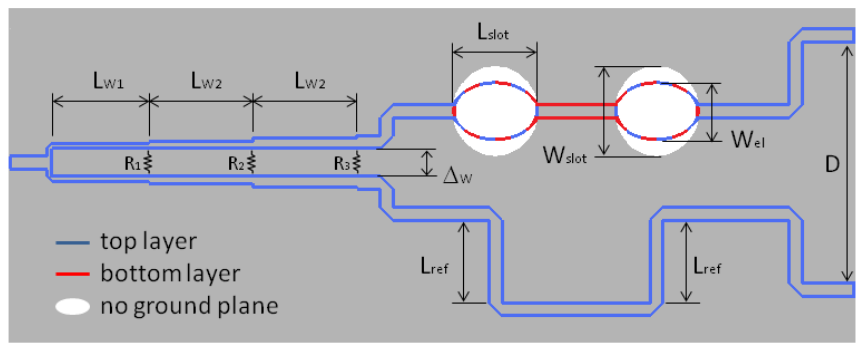

Figure 3. Detailed structure of the feed network.

\section{B. Antenna configuration}

Two end-fire antipodal vivaldi antennas were designed, using spline curve shapes and an efficient global optimization algorithm [8]. Although for linear polarization the antipodal antennas are known for poor cross-polarization, for $\mathrm{CP}$ it is only necessary that both linearly cross-polarized components are the same.

Ideally the antennas should be spaced as close as possible, in order to keep both phase centers close. This is limited by the width of antenna plus spacing needed to prevent coupling. In the optimization process this was solved by fixing the most outer point of the spline curve as $(14,100)$, resulting in long but relatively narrow vivaldi antenna $(40 \mathrm{~mm}$, compared to i.e. $62 \mathrm{~mm}$ on $\varepsilon_{\mathrm{r}}=2.2$ in [4]). The optimized radiator can be described by a spline curve with control points: $(0.8,30),(0.8$, $32),(8.7,49.8),(18,93.3),(14,100),(-1,99),(-0.8,32)$ and $(-$ $0.8,30)$, which is mirrored on the other side of the substrate to form antipodal vivaldi. A third curve with control points: $(5.2,5),(3.2,28.7)$ and $(0.8,30)$ defines a balun from asymmetric $50 \Omega$ microstripline to symmetric slot.

\section{RESULTS}

Simulated results for proposed antenna exhibit $\mathrm{S}_{11}<-10 \mathrm{~dB}$ from $2.6 \mathrm{GHz}$ to $8.3 \mathrm{GHz}$ (plot not shown for brevity). Fig. 3 shows the simulated boresight AR for various antenna configurations. It is seen, that for the feed with two independent inputs, a good $\mathrm{AR}<3 \mathrm{~dB}$ is achieved in the band from 3 to $7.5 \mathrm{GHz}$. This performance degrades when simple Tjunction is applied due to poor isolation between two channels. A 3-stage Wilkinson divider solves the problem.

Fig. 4 shows a two-dimensional plot of the AR as a function of angle $\theta$ and frequency (for convenience all values above $6 \mathrm{~dB}$ are grey) for the antenna with 3-stage Wilkinson divider. The main lobe with LHCP occurs for $\theta=90^{\circ}$ and a back lobe with RHCP can be seen for $\theta=270^{\circ}$. It can be seen, that due to antenna proximity, a small tilt in the main beam is present. Also the CP beam gets narrower with increased frequency, as the electrical distance increases. A comparable problem occurs for classical linearly polarized UWB antenna arrays [3].

\section{ACKNOWLEDGEMENT}

This publication has emanated from research conducted with the financial support of Science Foundation Ireland under Grant Number 09/SIRG/I1644.
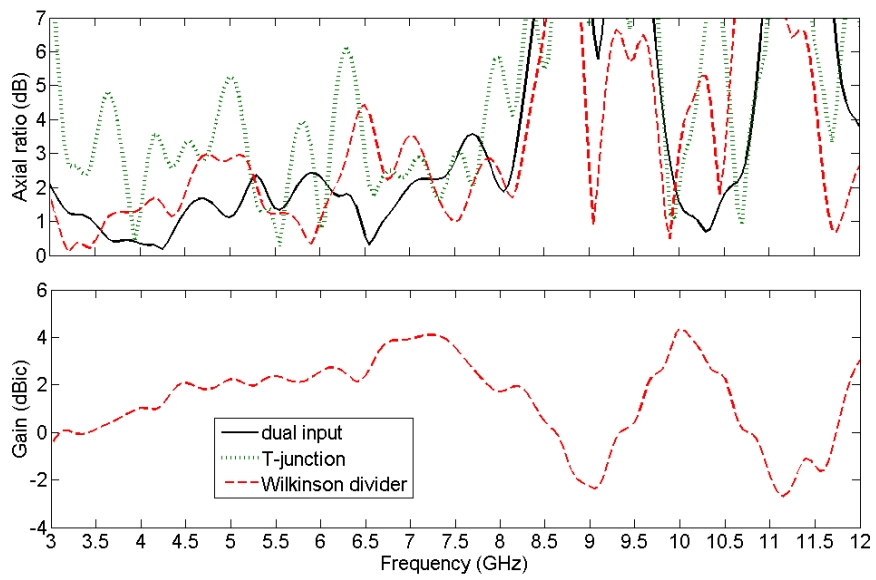

Figure 3. LHCP gain and axial ratio for boresight $\left(\theta=90^{\circ}\right)$.

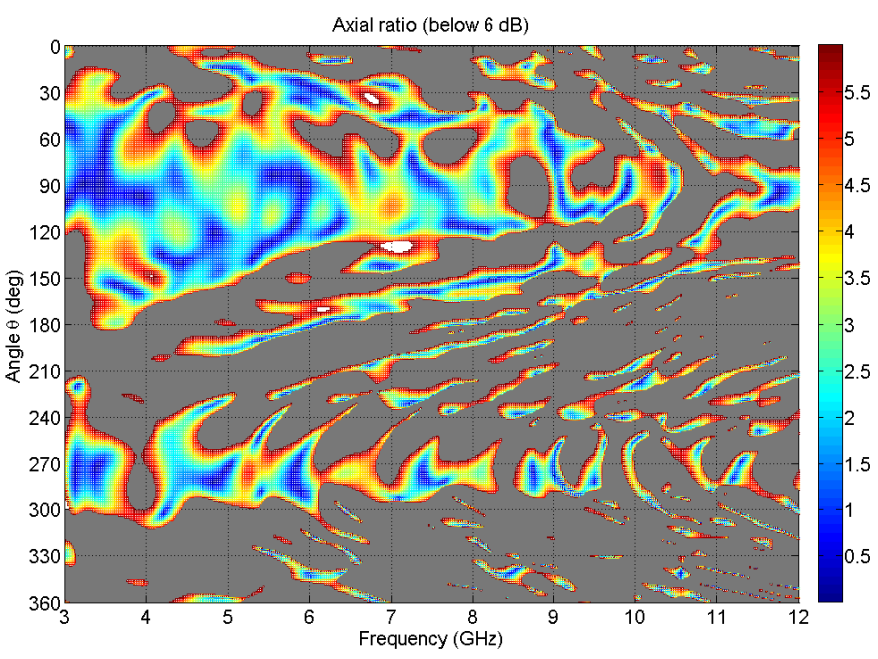

Figure 4. Axial ratio as a function of angle and frequency.

\section{REFERENCES}

[1] X.L. Bao, and M.J. Ammann, "Printed circularly polarised antenna with ultra-wide axial-ratio bandwidth," IET Microwaves, Antennas \& Propagation, vol. 5, pp. 1089-1096, June 2011.

[2] A.M. Abbosh, "Ultra-Wideband Phase Shifters", IEEE Trans. Microwave Theory Tech., 55, (9), pp. 1935-1941, 2007.

[3] A. Narbudowicz, G. Adamiuk, and W. Zieniutycz "Clover Array Polarisation Diversity Solution for Ultra Wideband Systems", Progress In Electromagnetic Research Letters, vol. 10, pp. 163-170, August 2009.

[4] G. Adamiuk, T. Zwick, and W. Wiesbeck "Dual-orthogonal polarized Vivaldi antenna for ultra wideband applications", MIKON - Int. Conf. on Microwave, Radar and Wireless Comm., Wroclaw 2008, pp. 1-4.

[5] Z. Hradecky, and P. Hamouz "Research of Circular Polarisation Quality by Using Quad Ridged Horn Antenna", EuCAP - European Conf. on Antennas and Propagation, Barcelona 2010, pp. 1-5.

[6] M.E. Bialkowski, and A.M. Abbosh, "Design of a Compact UWB Outof-Phase Power Divider", IEEE Microwave and Wireless Compontnts Letters, vol. 17, pp. 289-291, April 2007.

[7] S.B. Cohn, "A Class of Broadband Three-Port TEM-Mode Hybrids", IEEE Trans. Microwave Theory Tech, vol 19, (2), 110-116, 1968.

[8] M. John, and M.J. Ammann, "Antenna Optimisation with a Computationally Efficient Multiobjective Evolutionary Algorithm" IEEE Trans. Antennas \& Propagat, vol. 57, (1), pp. 260-263, 2009. 